\title{
LA RENOVACIÓN IDEOLÓGICA DE LA DERECHA RADICAL VALENCIANA
}

Anna I. López Ortega
Universitat de València'

http://dx.doi.org/10.5209/NOMA.54766

\begin{abstract}
Resumen.- La explotación de la multiculturalidad y la inmigración desde el partido político España 2000 es un síntoma evidente de la modernización del discurso la extrema derecha valenciana. Además, supone uno de los elementos para la identificación de esta tipología de partidos políticos. El objetivo principal es analizar, por primera vez en el ámbito académico, los elementos fundamentales de la ideología de E2000 partiendo del análisis teórico-conceptual de Totalismo Ideológico formulado por Robert Jay Lfton y comprobar que el discurso de este partido agrupa los componentes que posibilitan calificarlo de extrema derecha contemporánea. Para ello, se estudian los testimonios más destacados de los líderes del partido a través de artícúlos de periódico y publicaciones de redes sociales publicados durante los 6 días de duración de un conflicto sucedido en Valencia por un monumento fallero de temática hindú. Los resultados contribuyen a comprender las nuevas líneas discursivas y propagandísticas de E2000, su impacto en la en la configuración de la opinión pública y el acercamiento ideológico a otras formaciones europeas.
\end{abstract}

Palabras clave: multiculturalidad, inmigración, derecha radical populista, ideología, España 2000, Totalismo Ideológico.

\section{The ideological renewal of the radical Valencian right}

Summary.- The exploitation of multiculturalism and immigration from the political party Spain 2000 is an obvious symptom of the discourse modernization of the extreme right Valencian. In addition, it is one of the elements for the identification of this typology of political parties. The main objective is to analyze, for the first time in the academic field, the fundamental elements of the ideology of E2000 starting from the theoreticalconceptual analysis of Ideological Totalism formulated by Robert Jay Lfton and to verify that the discourse of this party groups the components that make possible to qualify it Of the contemporary extreme right. To this end, the most outstanding testimonies of the party leaders are studied through newspaper articles and social media publications published during the 6 days of a conflict that happened in Valencia by a fallero monument of Indian theme. The results contribute to understanding the new discursive and propagandistic lines of E2000, its impact on the configuration of public opinion and the ideological approach to other European formations.

Keywords: multiculturalism, immigration, populist radical right, ideology, España 2000 Ideological Totalism.

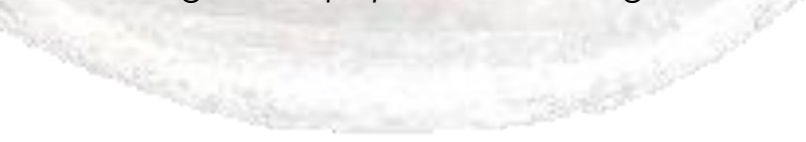

\section{Introducción: Objetivos y metodología}

El objetivo principal de la investigación es el análisis del discurso e ideologia del partido político España 2000 partiendo del modelo formulado por Robert Jay Lifton (1989) que estudia los componentes del

\footnotetext{
' Departamento de Ciencias Politicas y de la Administración. Valencia. España
} 
discurso de la extrema derecha contemporánea. Comprobaremos en qué medida E2000 puede ser considerado, por primera vez en el ámbito académico, como parte de esta família de partidos que está cosechando buenos resultados electorales en la Unión Europea.

La metodología empleada es la recopilación de documentación de los testimonios de los diferentes actores implicados (líderes del partidos, autoridades, comunidad hindú) en un conflicto sucedido durante 6 días en las fallas de Valencia de 2014 por un monumento fallero que contenía figuras hindús. No se realiza un análisis del contenido, sino que se aplica el esquema de Robert Jay Lifton (1989) para examinar la propia naturaleza elusiva del discurso de la extrema derecha valenciana, los elementos performativos que lo caracterizan y que pueden influir en el voto y las actitudes de los ciudadanos.

En primer lugar, se realiza un breve análisis de las características discursivas, resultados electorales y propaganda de los partidos de extrema derecha europeos a través de la bibliografía especializada. A continuación se analizan los diferentes actores implicados en el conflicto sucedido en el barrio valenciano de Tres Forques (falleros, representantes comunidad hindú, autoridades locales y militantes y líderes de E2000) durante la celebración de la fiesta de las Fallas en marzo de 2013 por un monumento con figuras hindús.

En la segunda parte, se analiza al agente creador del conflicto, el partido político de derecha radical populista valenciana, E2000, a partir de la aplicación del modelo de Totalismo Ideológico a través de los testimonios utilizados por sus líderes y militantes. El hecho novedoso es la adopción de este discurso populista y anti inmigración por parte de E2000.

\section{Aproximación a la derecha radical populista europea}

Los efectos de la crisis mundial de 2007 desembocaron en la insatisfacción ciudadana con los sistemas de gobierno tradicionales, incapaces de resolver problemas de la mundialización. Al mismo tiempo, esta crisis ha favorecido el crecimiento de los partidos calificados calificadas en la década de los ochenta de "ola populista» (Taguieff, 2007) y más tarde de "nueva extrema derecha», (Rodríguez, 2006), «populismo de derecha radical»- (Betz, 2004), o «derecha radical populista» (Mudde, 2007).

Los resultados obtenidos por algunas de estas formaciones en las elecciones europeas de mayo del $2014^{2}$ han situado este fenómeno en

\footnotetext{
2 Los diputados pertenecientes a partidos de extrema derecha están inscritos en el Grupo Europa de las Naciones y la Libertad y en el de No inscritos y de forma minoritària en el grupo de Conservadores y Reformistas. Para más información
} 
el centro de la agenda mediática europea (Antón Mellón y Hernández Carr, 2015: 4)

Las temáticas usadas por estas formaciones como motor de su movilización política se han centrado principalmente en dos temas: la construcción del imaginario y un discurso de rechazo frontal a la población extranjera (Antón Mellón y Hernández Carr, 2016: 4).

De esta manera, sus esfuerzos se han centrado en captar el voto de protesta de la ciudadanía, cansada y desorientada ante el colapso del sistema democrático actual. Así, la ciudadanía encuentra es estos partidos una supuesta respuesta a sus preocupaciones a través de soluciones concretas y sencillas y en las que la frustración identifica a un enemigo común: la población extranjera que se identifica como la responsable de sus problemas y, como consecuencia, debe quedar fuera del sistema. Un discurso xenófobo legitimado por esta familia de partidos en la Unión Europea (Frente Nacional, Partido por la Libertad, Alternativa para Alemania, Amanecer Dorado, Plataforma per Catalunya, España 2000).

En todos estos casos, los discursos de la derecha radical populista asocian tres conceptos: inseguridad, criminalidad e inmigración. Desde esta posición han ejercido un papel fundamental en el endurecimiento de medidas de control de las fronteras o políticas de integración en las sociedades de acogida. Señala Rydgren (2005:36) que la exitosa movilización política de estas formaciones se ha construido "a partir de un etno-nacionalismo basado en el "racismo cultural" y una retórica populista, pero no antidemocrática ni anti-establishment político»

Al fin y al cabo, conviene no olvidar lo que antropólogos expertos en esta materia como Wieviorka advierten: la xenofobia constituye la demarcación social de un ellos separado del nosotros (en todas sus múltiples variedades: desde las clases sociales a las razas, pasando por las naciones) y es un elemento casi consubstancial al proceso de civilización (Wieviorka, 1992; 36). Como resultado, la xenofobia ha calado en amplias capas de la población por su alta efectividad de disipar y disimular las propias culpas: si hay poco trabajo, que se lo den a los de aquí o se aprovechan de nuestra sanidad.

En este sentido, la derecha radical populista se ha convertido en un acto determinante e incluso protagonista-por ser el promotor del problema-en muchos de los conflictos en el ámbito local y con ciudadanos de diferentes culturas y religiones, que es donde mayor rentabilidad electoral por la combinación de dos factores: un discurso anti inmigración con fuerte carga emocional, donde apelan a sentimientos profundamente anclados en la naturaleza humana, como el miedo al diferente y un activismo "a pie de calle» (Erra y Serra, 2008:

consultar web del Parlamento Europeo: http://www.europarl.europa.eu/elections2014results/es/election-results-2014.html 
16). Sobre esta cuestión, Hernández Carr (2011: 67) en el estudio sobre el discurso de PxC, asegura que ula inmigración es sin duda un elemento central en este activismo local [...] La actividad de "captación" de quejas y conflictos vecinales no se limita a la temática inmigratoria»».

Al mismo tiempo, la cuestión de la inmigración se percibe por los ciudadanos de toda la Unión Europea como un problema, especialmente, tras la crisis de los refugiados por la guerra en Siria. El Eurobarómetro de noviembre de 2015 señala que el $39 \%$ de los españoles consideran la inmigración como el primer problema de la UE por delante incluso del terrorismo (24\%), la situación económica (24\%), el paro (25\%). (Comisión Europea 2015: 38). La respuesta mayoritaria también se extiende al resto de los 28 Estados de forma unánime.

También es cierto que el porcentaje de preocupados por este problema en España es uno de los menores de todos los países europeos (en Estonia el $79 \%$ de los encuestados identifica inmigración como el problema más importante de la UE, mientras que en la República Checa, Dinamarca y Alemania es el $76 \%$ ) en el nivel nacional, los problemas económicos ocupan el primer lugar., en concreto al $69 \%$ de los españoles lo que más le preocupa es el paro, y este porcentaje es el más alto entre todos los países europeos.

Estos datos han sido corroborados por otra estadística de Eurostat del 29 de julio de 2016 que manifiestan que los europeos ven la inmigración y el terrorismo como los principales desafíos que enfrenta la UE en este momento (Comisión Europea, 2016: 17)

Por otro lado, los conflictos raciales y religiosos derivados de la inmigración son más recientes en España que en otros países de la UE, como Francia o Alemania porque España se convirtió en un país receptor de inmigración económica sólo a partir de los primeros años del siglo XXI. Por ejemplo, en el año 2000 tenía una tasa de inmigración del 2,3\% y diez años más tarde del 12,2\%. En el 2016 la cifra ha descendido apenas 3 puntos (Gráfico 1) 
Gráfico 1. Evolución de la tasa de inmigración en España (2000-2016)

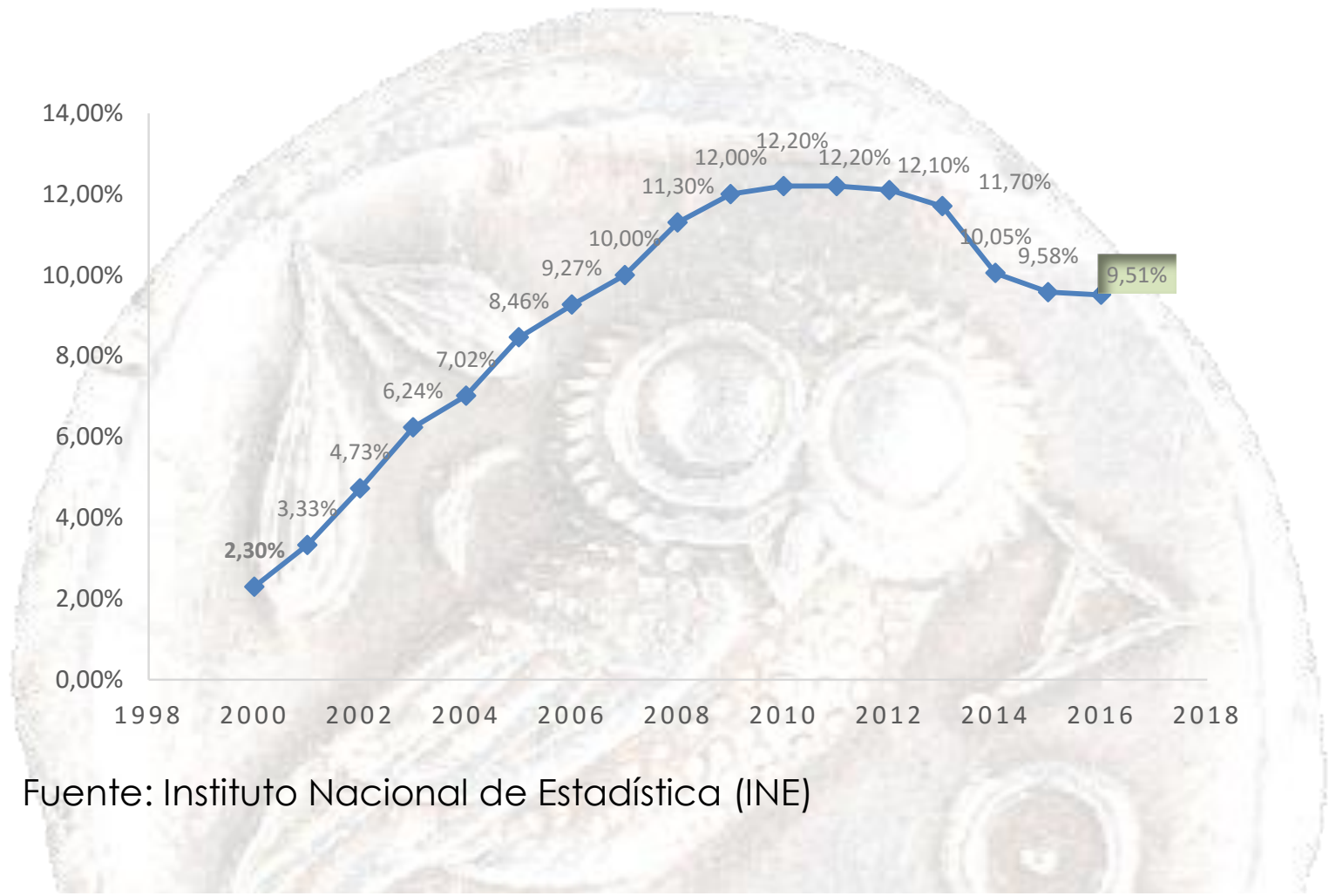

Por este motivo, a partir de mediados del 2000 y tras la crisis económica de 2007, las evidentes diferencias étnicas, raciales, culturales y religiosas -especialmente con la población magrebí y subsahariana- motivaron conflictos de convivencia entre la población española. El informe anual de delitos de odio en España que se elabora desde 2011 desde el Ministerio del Interior, revela como han aumentado los actos de violencia, racismo y xenofobia hacia esta parte de la ciudadanía. En concreto, en 2011 se registraron 92 y cuatro años más tarde 1.285. (Gráfico 2). 
Gráfico 2. Evolución delitos de odio en España 2011-2015

Evolucion delitos de odio L L Lineal (Evolucion delitos de odio)

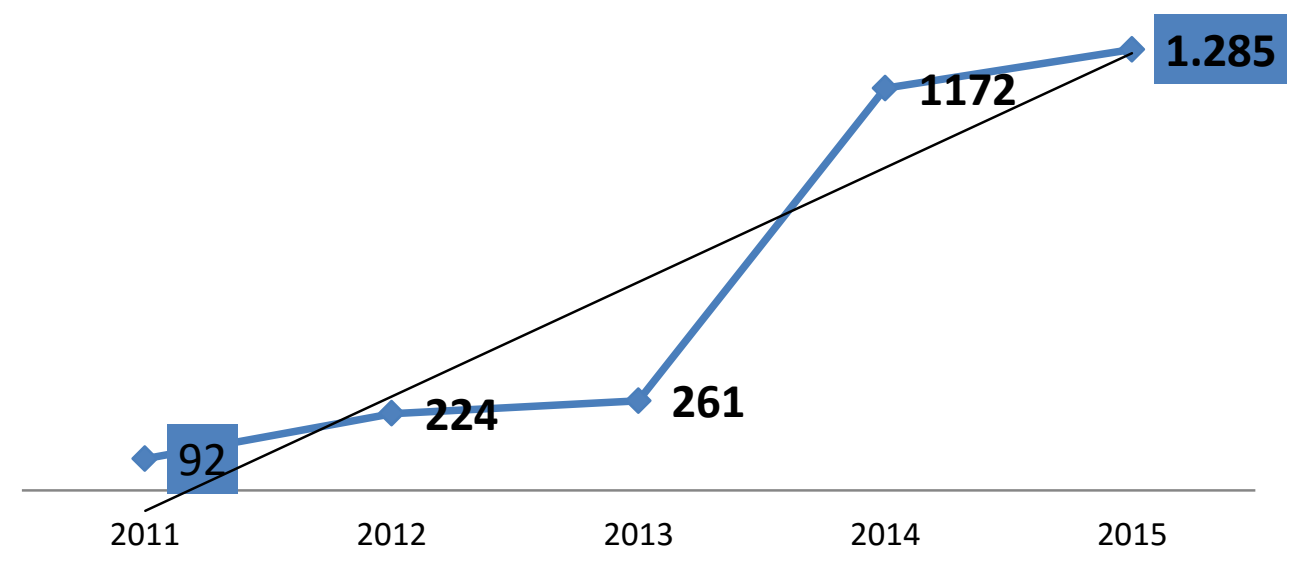

Fuente: Ministerio del Interior de España e Informe Raxen (2011-2015)

También es cierto que el concepto de delito de odio era desconocido hace una década. Precisamente este desconocimiento ha provocado un debate en torno a su propia existencia, justificación y regulación por dos motivos: la determinación sobre qué grupos o personas deberían estar consideradas como víctimas del odio y la dificultad de su consenso internacional, ya que en muchas ocasiones en una cuestión de la problemática interna de los estados.

La definición de delito de odio aprobada desde el Consejo Ministerial de la Organización para la Seguridad y la Cooperación en Europea (OSCE) celebrado en Maastricht en 2003 y utilizada por el Ministerio del Interior de España, define los delitos de odio como:

"toda infracción penal, incluidas las cometidas contra las personas o la propiedad, donde el bien jurídico protegido, se elige por su, real o percibida, conexión, simpatía, filiación, apoyo o pertenencia a un grupo. Este grupo se basa en una característica común de sus miembros, como su "raza", real o percibida, el origen nacional o étnico, el lenguaje, el color, la religión, la edad, la discapacidad, la orientación sexual, u otro factor similar". (Decisión n 4/03 de la OSCE).

Algunos ejemplos de este tipo de delito en España también se denuncian en el Informe Raxen elaborado por Movimiento contra la Intolerancia (2014: 80) donde recogen páginas de facebook como "Mata a los negros", con la imagen de un negro colgando de una soga, "Odio a las gitanos", "Contra la invasión inmigrante", "Rudolf Hess vive", "Mata gays", "Hay que legalizar la violación", "Odio a los maricones, las 
putas y los policías" y centenares de páginas donde se incita al odio, la discriminación o la violencia hacia colectivos vulnerables.

\section{Análisis del conflicto y del actor principal: España 2000}

España 2000 se constituye oficialmente como partido político en 2002 en la ciudad de Valencia y está presidido por José Luis Roberto. El líder es un empresario y abogado vinculado a la ultraderecha y a empresas de prostitución y de seguridad. Antes de fündar E2000, Roberto lideró la Plataforma España 2000 que concurrió en las elecciones generales por primera vez en el año 2000 y obtuvo 1.516 votos $(0,06 \%)$. Este proyecto apenas tuvo dos años de vida.

En el año 2002, E2000 tiene poco más de 3.300 afiliados, mayoritariamente en la Comunidades Valenciana y en la ciudad de Madrid. El partido concurre por primera vez los comicios autonómicos valencianos de 2003 y obtiene 2.650 votos, un año más tarde, en las elecciones nacionales logra 4.231 votos (Tabla 1).

La formación ha alcanzado su mejor resultado en las elecciones autonómicas de 2011 ya que consigue más de 12.000 votos. Estos resultados duplican las cifras de los comicios de 2007 y quintuplican los de 2003 y 2004. Además la formación recibió votos en el $95 \%$ de los municipios valencianos y consiguió 5 concejales, uno de ellos, fuera de la Comunitat Valenciana, concretamente en Alcalá de Henares la segunda ciudad más poblada de Madrid. En Valencia obtuvieron más de $70 \%$ de los votos, mientras que Alicante y Castellón se reparten alrededor de un $15 \%$ de las papeletas.

Sin embargo, en 2015 el partido pierde 1.810 votos tanto en las elecciones autonómicas como en las locales y renuncia a presentarse en las legislativas y europeas. Al mismo tiempo, aumenta su implantación territorial en el ámbito local que a través de la apertura 32 sedes en la Comunitat Valenciana, acompañado de una mayor presencia en los medios de comunicación tradicionales, Internet y su presencia activa en la calle a través de manifestaciones.

Tabla 1. Evolución electoral de España 2000 en las elecciones locales, autonómicas y nacionales 2002-2015

\begin{tabular}{|l|l|l|}
\hline & Elecciones & $\begin{array}{l}\text { Votos } \\
\text { Representantes }\end{array}$ \\
\hline 2003 & Locales & 998 \\
\hline 2003 & Autonómicas & 2650 \\
\hline 2004 & Legislativas & 2721 \\
\hline
\end{tabular}




\begin{tabular}{|l|l|l|}
\hline 2007 & Locales & 3790 \\
\hline 2007 & Autonómicas & 5934 \\
\hline 2008 & Legislativas & 3875 \\
\hline 2011 & Locales & 8066 \\
\hline 2011 & Autonómicas & 12191 \\
\hline 2015 & Locales & 5591 \\
\hline 2015 & Autonómicas & 7456 \\
\hline
\end{tabular}

Fuente: elaboración propia con datos del sistema de información ARGOS.

Su discurso está vertebrado principalmente en el populismo, autoritarismo y el nacionalismo, que caracterizan el núcleo ideológico de la derecha radical populista europea según la propuesta de Antón Mellón y Hernández Carr (2015: 5). Desde sus comienzos el partido se ha definido como upopulista, social y democrático» y ha rechazado cualquier adscripción a la izquierda o a la derecha del arco político, una característica que comparte con otros partidos de derecha radical populista europeos.

Así, su argumentario xenófobo presupone una migración masiva y responsable de los problemas de la sociedad española. Por este motivo, proponen medidas de expulsión de la población inmigrada como solución a los problemas detectados. Además, vinculan la inmigración con las consecuencias de la crisis, la falta de prestaciones sociales, la amenaza a la identidad cultural (en especial la migración musulmana), y reivindican un reforzamiento de la identidad propia considerándola como algo homogéneo y perfectamente definido. El partido defiende la prioridad nacional ante la competencia por los recursos y se presenta como única alternativa frente a los partidos políticos tradicionales, calificados de corruptos e incapaces de resolver los problemas de la sociedad. Sobre política exterior, culpabiliza a la Unión Europea de la mayoría de los problemas de España y defiende el euroescepticismo, reivindicando la recuperación del poder del gobierno sóberano y de la gestión de la propia economía.

Con estas características, E2000 desplegó su estrategia local durante las fallas de Valencia en $2013^{3}$ cuando la comisión Ceramista Ros, ubicada en el barrio de Tres Forques, plantò un monumento que contenía representaciones de divinidades del brahmanismo como Saravati, la diosa del conocimiento y la justicia o el dios Ganesha, en forma de elefante, que era la figura central. El presidente del Templo Hindú de Valencia, Swani Omkrananda, señaló no había ningún 
problema por la representación de las figuras, ya que "en muchos templos del sur de la India hay muchas representaciones de divinidades védicas que se asemejan $-\mathrm{y}$ mucho- a las típicas representaciones falleras» (Pitarch, 2013).

El problema en este caso era quemarla ya que este acto suponía "mancillar las tradiciones hindúes".

Para resolver el conflicto, las asociaciones hindúes en Valencia enviaron un escrito con carácter de urgencia a la Junta Central Fallera de Valencia y la alcaldía de Valencia y pidieron la solicitud de amparo a la Delegación de Gobierno para impedir que el monumento se quemara con estas divinidades. En pos, en la Comisión Fallera se reunieron los sacerdotes del Templo hindú de Valencia.

Para resolver el conflicto, Las asociaciones hindús en Valencia realizan un escrito con carácter de urgencia a la Junta Central Fallera de Valencia y alcaldía de Valencia, y solicitaron un recurso de amparo a la Delegación de Gobierno para impedir que el monumento quemara esas divinidades. A posterio en la Comisión Fallera se reúnen los sacerdotes del Templo hindú de Valencia con un traductor. El presidente de la Falla insistía en un primer momento en que «el "umonumento se quemaría sí o sí» (Bernabeú, 2013). El artista fallero, creador del monumento, argumentaba que había elegido la temática hindú porque use podía sacar mucho partido a la falla gracias al colorido de la India y pensé que a la gente le podría gustar mucholl (Bernabeú, 2013).

El problema continuó y los representantes hinduistas valencianos llegaron a amenazar con un "conflicto internacional» e incluso un pakistaní amagó con quemarse a lo bonzo antes de la cremà de la Falla. No obstante, la resolución del conflicto fue pacífica, ya que el monumento fue quemado, previa mutilación de aquellos elementos icónicos que permitían identificar a las divinidades.

Este hecho, que podría considerarse anecdótico, ocupó durante varios días las portadas de los periódicos locales e incluso informativos nacionales. Además propició la reacción inmediata de la extrema derecha valenciana. La polémica vino acompañada de constantes alusiones a este partido y a sus posturas restrictivas en materia de inmigración y sobre la incompatibilidad cultural y religiosa.

En este sentido, E2000 apareció en la escena política de diferentes maneras como a continuación se expone:

Primero cuando se retiraron los elementos que, en virtud de un acuerdo entre las partes, fueron mutilados de la Falla para poder quemarla. En este momento, un grupo militantes de E2000 protestaban voceando consignas: "español, defiende tu nación" e incluso en su web publicaron una noticia y una imagen que divulgaron por las redes 
sociales con el lema "Si la tradición muere, tu pueblo también" (Figura $1)$.

Figura 1. Imagen difundida por el partido político España 2000.

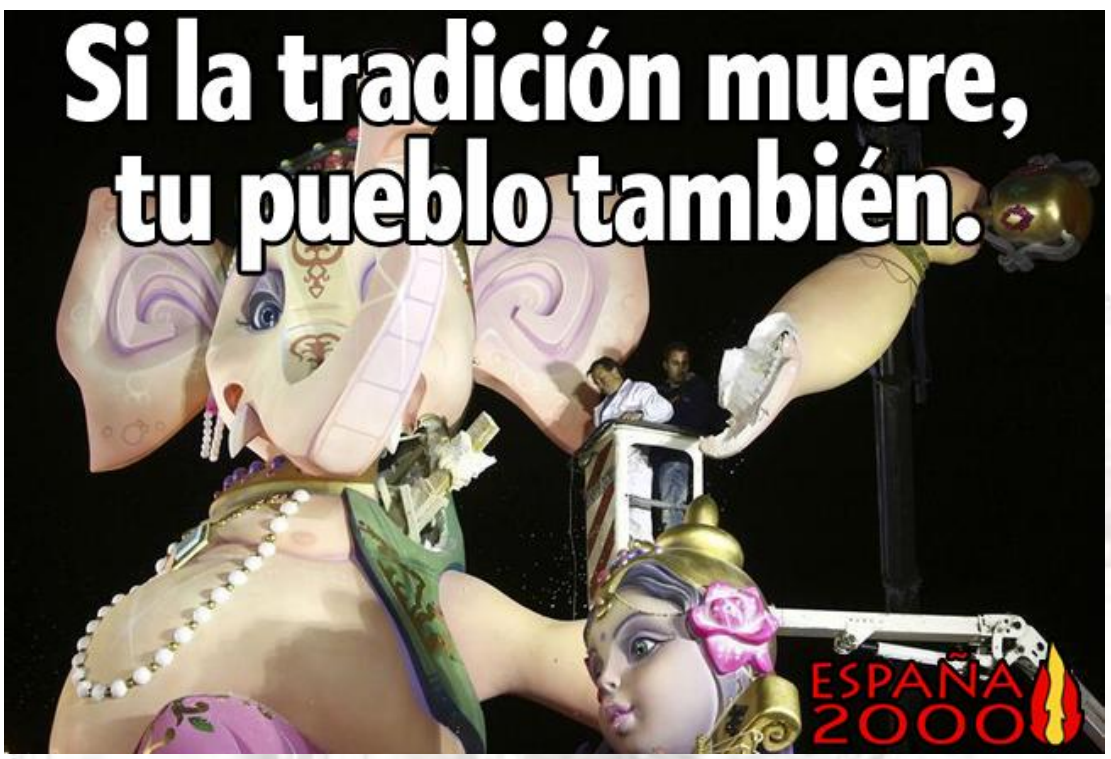

Fuente: web de España 2000. Recuperado el 2 se septiembre de 2016 del sitio web http://espana2000.org/? $p=1216 \#$ more-1216

Pero la consigna más llamativa de todas era la otra, la que afirmaba: «España, cristiana y nunca musulmana». Es decir, aplicaban el eslogan arquetípico de la islamofobia, uno de los tópicos recurrentes de su ideario, aunque no tenía nada que ver con la religión musulmana, sino con la hindú.

Aunque puede parecer un asunto aislado, este acto es más bien un síntoma genérico y no solo español ni valenciano de que la nueva extrema derecha europea aprovecha cualquier atisbo de conflicto social de tintes xenófobos para visibilizar su ideología. Una excusa para dejarse ver, para crear, alentar y participar en el escándalo.

Responde a una estrategia de visibilización que ha crecido exponencialmente a raíz de la crisis económica y con consecuencias sociales: en las manifestaciones en Alemania protagonizadas por la plataforma islamófoba, Pegida, en las protestas también islamófobas en Francia tras los atentados de enero de 2015 al semanario Charlie Hebdo. Sin olvidar la matanza perpetrada por Anders Breivick en la isla de Utoya en julio de 2011. En el juicio manifestó que «actuaba en nombre de la lucha contra el multiculturalismo y la invasión musulmana» (El País, 2015).

En este sentido, esta estrategia parece darles buenos y suculentos réditos electorales en prácticamente en todos los países de la Unión 
Europea: Alternativa para Alemania en Berlín, que ha logrado el 14\% de apoyos en los últimos comicios celebrado en octubre de 2016; Amanecer Dorado, el Frente Nacional, el Partido de la Libertad austriaco o el Vlaams Belang flamenco.

Tras el análisis de los testimonios de los diferentes actores en el conflicto valenciano, destacan algunos de los argumentos para defender sus posiciones:

1) Los vecinos de la Falla de Valencia apelaban "a los usos y costumbres») (Bernabeú, 2013).

2) Los representantes del templo hindú reivindicaban el artículo 16 de la Constitución española, que alude al derecho fundamental de libertad religiosa.

3) El secretario de la Junta Metropolitana de E2000, Juan Broch que manifestó en la red social Facebook ${ }^{4}$ "uafortunadamente para nosotros, fueron pocos, si nos hubiéramos juntado 50 o 100 personas, posiblemente ese muñeco hubiera ardido con los hindúes dentro» (Parrilla, 2013);

4) El presidente de E2000, José Luis Roberto, escribió un artículo de opinión tres días después de la nit de la cremà (20 de marzo) con un título más que elocuente: «Intégrate o vete" (Levante, 2013: 5) y que concluía con las siguientes palabras:

«El extranjero cuando está en otro país, al igual que hacemos los españoles, tiene la obligación de adaptarse a sus costumbres y tradiciones y en ningún sitio, excepto aquí, se permite que se imponga lo foráneo frente a lo propioı) (Levante, 2013: 5).

\section{El Totalismo Ideológico de España $\mathbf{2 0 0 0}$}

Los discuros de Juan Broch y José Luis Roberto son una muestra de lo que Robert Jay Lifton en su análisis del totalismo ideológico, denominaba «el carácter performativo de ciertos discursos: lo importante no es tanto qué dicen como las reacciones que generan» (Jay Lifton, 1989: 26)

Se trata de discursos con una fuerte carga emocional que apelan a sentimientos profundamente anclados en la naturaleza humana como el miedo al otro y al diferente, sobre todo si ese otro es racial y

\footnotetext{
4 Juan Broch publicó en su facebook el 14 de marzo de 2013 "estamos aquí —en el partido, se refiere Broch - para defender lo nuestro, nuestra cultura y tradición". Y seguía con un mensaje que buscaba un auditorio más amplio, no el de sus correligionarios: "es muy bonito quedarse en casa y luego criticar a esa gente que fue a impedir que se llevaran esa parte de la falla". "¿Dónde está la gente joven? ¿̀Hasta cuándo va a durar esto?", decía. "Ayer ganaron con un simple muñeco ¿̇y mañana qué será? , se preguntaba antes de concluir antes que "ya va siendo hora de actuar".
} 
religiosamente distinto. Un discurso propio de la extrema derecha contemporánea.

Pero las protestas de la militancia de E2000, los artículos de Broch y Roberto comparten más características del discurso totalista, según lo define Jay Lifton (1989).

1) La carga del lenguaje que busca resolver cuestiones complejas con clichés

lingüísticos más socialmente digeribles. A este respecto, Juan Broch manifestó: "Ayer ganaron con un simple muñeco ¿̇y mañana qué será?» (Parrilla, 2013). Según los parámetros de Lifton aplicados a este caso, la acción de ganar no está elegida de forma trivial, unos ganan y oros pierden.

1) La manipulación mística o espontaneidad planeada, aquella que intenta provocar desde arriba emociones y pautas específicas de comportamiento que parezcan, en cambio, haber surgido espontáneamente del entorno. En este caso, los militantes de E2000 convocaron una manifestación en el momento que se retiraban las figuras de dioses hindús (en virtud de un acuerdo entre las partes) en las que interpelaban y buscaban la aquiescencia natural de los transeúntes y vecinos con consignas como "español, defiende tu nación».

2) La demanda de pureza. Este rasgo se visualiza en las consignas de los manifestantes de E2000: «España, cristiana y nunca musulmana».

3) La división entre puros e impuros, buenos y malos, civilizados o no. Para José Luis Roberto, por ejemplo:

"la comunidad hindú tiene una ultraortodoxa religiosidad trasnochada en una sociedad civilizada o europea" [...] una religión que se identifica por el sistema de castas, por la explotación laboral de la infancia y por la falta de derechos de la mujer no es sujeto para exigir respeto» (Levante, 2013:5).

4) El victimismo que cree y hace ver en todas partes amenazas y complots contra el país y los puros nacionales, racial y religiosamente. En este sentido, Roberto señala:

«Que una comunidad como la hindú amenace con el presumible levantamiento de 800 millones de hindús [... ] Que amenace a los miembros de la falla [... ], que actúe de esa manera sólo puede calificarse en el Código Penal como coacción... son ellos, los otros, los que nos amenazanu (Levante 2013:5) . 
Finalmente, el presidente de E2000 concluye su artículo proponiendo con una lema, "uel tema es sencillo: hay que conservar la identidad, las costumbres y las tradiciones y la respuesta a las presiones es Intégrate o vete» (Levante, 2013: 5).

\section{Conclusión}

Aunque el conflicto sucedido en el barrio valenciano de Tres Forques puede parecer una cuestión anecdótica y local, se trata del reflejo de una estrategia de movilización en la familia de la derecha radical populista. Además, en esta estrategia ocupa un lugar destacado la búsqueda de una cierta transparencia o neutralidad discursiva con el objetivo de suavizar las aristas más problemáticas de su discurso tradicional y en cambio, captar prosélitos en nuevos caladeros electorales.

Su modus operandi se caracteriza en aumentar su presencia ante la opinión pública y los conflictos multiculturales son una excelencia • lento ocasión porque se trata de un tema que concita una mayor -y más natural- unanimidad, casi pre-racional: el rechazo del otro por ser diferente y en este caso, por cuestiones religiosas. En este caso, protagonizado por la formación valenciana E2000, que no estaba considerada -dentro del ámbito académico- como parte de esta familia de partidos y en consecuencia, tampoco su nueva ideología. Entre los motivos más destacados, por la vinculación de su presidente y algunos militantes al régimen franquista. Además, el análisis de los testimonios de los principales líderes y militantes de E2000 a partir del modelo de totalismo ideológico de Robert Jay Lifton en este conflicto ha permitido examinar la ideología del partido y comprobar cómo agrupa, en diferente grado, pero de una manera clara, todos los componentes (carga del lenguaje, manipulación mística, demanda de pureza, victimismo) que posibilitan definir al discurso de la formación como propio de la extrema derecha contemporánea.

En este contexto y a pesar de que la presencia en la opinión pública de la extrema derecha española y valenciana pueda parecer marginal -e incluso aislada-, no puede pasar desapercibida para los actores y gestores políticos, especialmente en el ámbito local, donde este tipo de acciones son más frecuentes e impregnan la opinión de los ciudadanos.

En el caso español, la extrema derecha está activa pero su estado es demasiado fragmentario. Se caracteriza por mantener cierta nostalgia del pasado franquista y por eso mismo, carece de un proyecto de futuro unificado. Es cierto que en octubre de 2015 se formó la plataforma RESPETO, uniendo varias facciones de la extrema derecha, incluyendo la valenciana con la catalana (E2000 y PxC). Sin embargo, todavía carecen de un líder carismático, un rostro visual e intelectualmente atractivo como lo fue Pim Fortuyn en Holanda, Jörg 
Haider y Norbert Hofer en Austria, Timo Soini en Dinamarca y Marine Le Pen en Francia,

Sin embargo, existen elementos que permiten pensar que se está transformando. Por ejemplo, su presencia activa en la calle en manifestaciones, actos protesta y apertura de nuevas sedes locales. Pero también en las más de 10.000 (López, 2015: 12) webs que propagan su ideología, su mayor profesionalización, voluntad comunicativa. Un nuevo medio de propaganda en el que los contenidos nostálgicos (los símbolos, iconos y textos franquistas) tienden a desaparecer en favor de una agenda más actualizada en la que figura -y de manera muy destacada-la inmigración, el multiculturalismo y la xenofobia.

\section{Bibliografía}

Antón Mellón, J. y Hernandez-Carr, A. (2016). El crecimiento electoral de la derecha radical populista en Europa: parámetros ideológicos y motivaciones sociales. Política y Sociedad, 53, 17-28

Bernabeú, L. (19 de marzo 2013). Fieles hindúes exigen a una falla que no que me sus símbolos religiosos. Levante EMV. Descargado de http://www.levante-emv.com/valencia/2013/03/19/fieles-hindues-

exigen-falla-queme-simbolos-religiosos/983052.html

Bommes, M y Geddes, A. (2000). Immigration and Welfare. Challenging the borders of the welfare state. Londres: Routledge.

Cea d'Ancona, A. (2004). La activación de la xenofobia en España. ¿Qué miden las encuestas?. Madrid: CIS

European Comission (2015). Standard Eurobarometer 82, Public opinion in the European Union. Brussels: Directorate General for Communication European Commission.

European Comission (2016). Standard Eurobarometer: Strong public support for Commission's political priorities. Brussels: Directorate General for Communication European Commission.

España 2000 (23 de marzo de 2013). España 2000 en defensa de la identidad valenciana. España 2000. Descargado de http://espana2000.org/?p=1216\#more-1216

El País (22 de julio de 2015). A cuatro años de la matanza en la isla de Utoya. El Pais. Descargado de htttp://elpais.com/elpais/2015/07/22/videos/1437561014_241449.html 
López, A. (2016). La estrategia de la nueva extrema derecha en Internet. Revista electrónica de recursos en Internet sobre geografia y ciencias sociales, 53, 1-23

Evans, J (2005). The Dynamics of Social Change in Radical Rightwing Populist Party Support. Comparative European Politics, 3, 76-101.

Lifton, J (1961). Thought Reform and The Psychology of Totalism. North Carolina: University of North Carolina Press.

Laclau, E. (2005). La razón populista. Buenos Aires: Fondo de cultura económica.

Levante- EMV. (23 de marzo 2013): Intégrate o vete. Levante EMV. Descargado de http://www.levanteemv.com/opinion/2013/03/22/integrate-o-vete/983762.html

Movimiento contra la Intolerancia (2012). Informe Especial Raxen. Europa en Crisis: Tolerancia o Barbarie: Racismo, Xenofobia e Intolerancia en Internet. Madrid: Movimiento contra la Intolerancia.

-(2014). Informe Raxen. Madrid: Movimiento contra la Intolerancia.

Mudde, C. (2000). The ideology of the extreme right. Manchester: Manchester University Press.

- (2007). Populist Radical Right Parties in Europe. Cambridge: Cambridge University Press.

Norris, P. (2005). Radical Right. Voters and Parties in the Electoral Market. Cambridge: Cambridge University Press.

Observatorio Español contra el Racismo y la Xenofobia (2010). Panel sobre discriminación por origen racial o étnico: la percepción de la posibles víctimas. Madrid: Ministerio de Empleo y Seguridad Social.

(2014). Inmigración, racismo y xenofobia en la España del nuevo contexto europeo. Madrid: Ministerio de Trabajo y Asuntos Sociales

Organización para la Seguridad y Cooperación europea (2003). Hate Crimes in the OSCE Región: Incidents and Responses. Polonia: OIDDH

Parrilla, J. (22de marzo 2013). Si nos hubiéramos juntado 100 personas ese muñeco habría ardido con los hindúes dentro. Levante EMV. Descargado de http://www.levanteemv.com/valencia/2013/03/22/hubieramos-juntado-100-personasmuneco-habria-ardido-hindues/983824.html

Rydgren, J. (2005). Is extreme right-wing populism contagious? Explaining the emergence of a new party family. European Journal of Political Research, 44, 413-37. 
Pitarch, S. (20 de marzo 2013). La falla Ceramista Ros arde tras horas de gran tensión y sin los símbolos sagrados hindúes. Levante EMV. Descargado de http://www.levanteemv.com/valencia/2013/03/20/falla-ceramista-ros-arde-horas-grantension-simbolos-sagrados-hindues/983275.html

Sartori, G. (2001). La sociedad multiétnica. Pluralismo, multiculturalismo y extranjeros. Madrid: Taurus.

Wieviorka, M. (1992). El espacio del racismo. Barcelona: Paidós Ibérica.

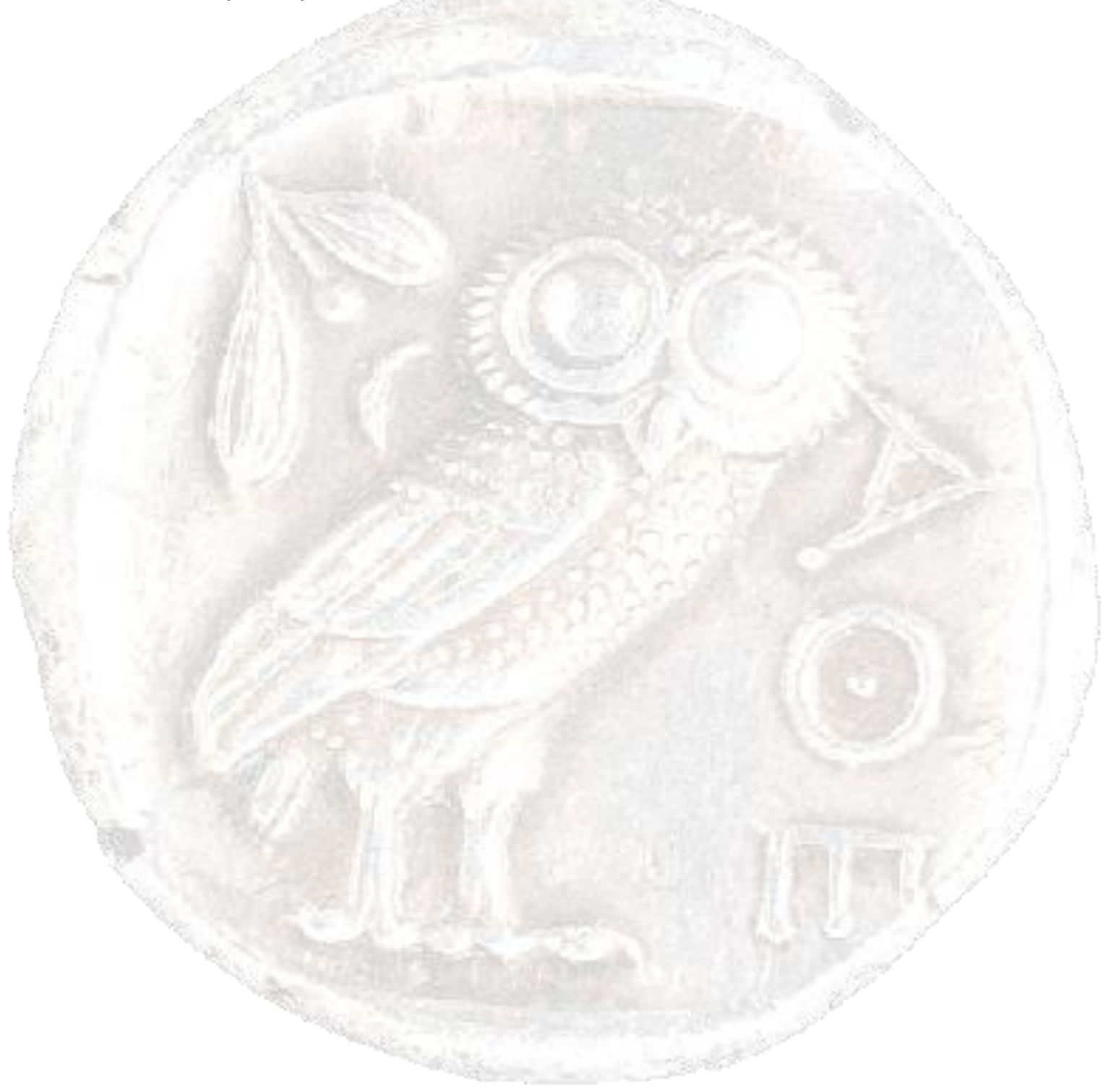

